\title{
Effect of Some Parameters on the Compressive Strength of MWCNT-Cement Composites
}

\author{
Hyukjin Choi, ${ }^{1}$ Donghoon Kang, ${ }^{2}$ Gang Seok Seo, ${ }^{1}$ and Wonseok Chung ${ }^{1}$ \\ ${ }^{1}$ Department of Civil Engineering, Kyung Hee University, Yongin-si, Gyeonggi-do 446-701, Republic of Korea \\ ${ }^{2}$ Advanced Materials Research Team, Korea Railroad Research Institute, 360-1 Woram-dong, Uiwang-si, \\ Gyeonggi-do 437-757, Republic of Korea \\ Correspondence should be addressed to Wonseok Chung; wschung@khu.ac.kr
}

Received 28 April 2015; Accepted 9 July 2015

Academic Editor: Peter Chang

Copyright (C) 2015 Hyukjin Choi et al. This is an open access article distributed under the Creative Commons Attribution License, which permits unrestricted use, distribution, and reproduction in any medium, provided the original work is properly cited.

\begin{abstract}
Enhancements in the compressive strength of ordinary Portland cement (OPC) mortar upon the incorporation of multiwalled carbon nanotubes (MWCNTs) were investigated. The MWCNT concentration, water/cement (W/C) ratio, curing age, and MWCNT concentration control method were selected as experimental parameters, and their effect on the compressive strength of the MWCNT-cement composites was examined. Here, the MWCNT concentration was varied from $0.25 \mathrm{wt} \%$ to $1.0 \mathrm{wt} \%$, while $\mathrm{W} / \mathrm{C}$ ratios in the range of 0.35 to 0.70 were employed. Curing ages of 7, 14, and 28 days were also utilized. To compare methods for controlling the MWCNT concentration, solutions were prepared by either adjusting the MWCNT content during mixing or controlling the MWCNT concentration by adding distilled water to solutions with a high MWCNT content. The compressive strength of the MWCNT-cement composites when considering the aforementioned parameters was compared to that of OPC mortar. Scanning electron microscopy (SEM) was also used to investigate the microstructure of the MWCNT-cement samples.
\end{abstract}

\section{Introduction}

Numerous studies have been conducted with the aim of improving the mechanical performance of cementitious materials via the incorporation of various types of fibers with outstanding mechanical properties. The utilization of nanotechnology to develop next-generation construction materials began in the mid-2000s and thus strategies to enhance construction material performance through the use of nanotechnology are still evolving. Consequently, methods to combine nanotechnology with construction materials have ample room for improvement.

In this work, enhancements in the compressive performance of cement are achieved by combining the material with carbon nanotubes (CNTs). CNTs can be classified as either single-walled carbon nanotubes (SWCNTs) or multiwalled carbon nanotubes (MWCNTs). While SWCNTs have higher Young's modulus, strength, and thermal conductivity when compared to MWCNTs, the use of the former in industrial applications is limited due to their high cost and difficulties associated with mass production. Although MWCNTs lack some of the desirable material properties of SWCNTs, they are still considered a useful material because of their relatively low cost, convenient mode of production, and easy dispersion. Hence, it is more practical to employ MWCNTs in cement composite applications, and many researchers have attempted to incorporate MWCNTs into cementitious materials.

Several research groups have investigated the use of MWCNTs in cementitious composites. Li et al. [1] examined the mechanical performance of cement composites by fixing the MWCNT concentration at $0.5 \mathrm{wt} \%$ and comparing the resulting compressive and flexural strengths to those of normal concrete. Cwirzen et al. [2] conducted a study whereby the compressive strength of cement mortar mixed with an aqueous solution of MWCNTs functionalized by carboxyl groups was compared to that of cement mortar mixed with a pure MWCNT solution. It was found that the carboxyl groups stabilized the MWCNTs within the composite mortar, thereby improving the compressive strength. Musso et al. [3] employed thermogravimetric analysis (TGA) and energy 
dispersive X-ray (EDX) spectroscopy to investigate the effect of CNTs on the compressive strength of cementitious composites as they absorb small amounts of water. It was demonstrated that excessive water content could prevent adequate hydration and thus degrade the compressive strength of cementitious composites. Chaipanich et al. [4] compared the strength of MWCNT-cement mortars with MWCNT concentrations of 0.5 and $1.0 \mathrm{wt} \%$ to that of OPC mortar. The authors found that the 0.5 and $1.0 \mathrm{wt} \% \mathrm{MWCNT}$ cement mortars had compressive strengths that were $7 \%$ and $9 \%$ higher, respectively, than that of OPC mortar.

Morsy et al. [5] concluded that MWCNTs reinforce the voids inside cement through a bridging effect. Kumar et al. [6] conducted compressive strength tests to determine the most appropriate curing age and MWCNT concentration for a mixture of MWCNTs and calcium silicate hydrate (C-S$\mathrm{H})$. The authors found that the compressive strength was highest for all curing ages when the MWCNT concentration was $0.5 \mathrm{wt} \%$. However, the compressive strength was lower when the MWCNT content was increased to $1.0 \mathrm{wt} \%$, as the MWCNTs inhibited hydration within the cement mortar. Hamzaoui et al. [7] conducted experiments using five relatively low MWCNT concentrations of $0.01 \mathrm{wt} \%$ to $0.06 \mathrm{wt} \%$. The compressive strengths of the resulting composites were higher than that of normal cement, indicating that the mechanical properties of cement can be improved even if a low-concentration MWCNT solution is employed in the mixture. Camacho et al. [8] found the compressive strength to be highest when the MWCNT concentration was $0.1 \mathrm{wt} \%$; higher MWCNT concentrations led to a decrease in the compressive strength. Bharj et al. [9] analyzed the compressive strength of cement mixed with either a $0.1 \mathrm{wt} \%$ MWCNT solution or $0.1 \mathrm{wt} \%$ MWCNT powder; curing ages of 7, 14, 28 , and 35 days were utilized for both sets of composites. The CNT structure and location in the cement were subsequently analyzed via scanning electron microscopy (SEM) and transmission electron microscopy (TEM).

Tanvir and Nur [10] performed an experiment to determine whether plasticizers affect the compressive strength of MWCNT-cement composites. It was found that the plasticizers improved the compressive strength of the composites by maintaining a stable dispersion of MWCNTs. Kang and Park [11] used mercury intrusion porosimetry (MIP) to confirm that the compressive strength of composites increased as the number of voids with a size of approximately $100 \mathrm{~nm}$ decreased. Consequently, it was concluded that physical features have a greater impact than chemical characteristics in terms of enhancing the compressive strength.

Nearly all studies to date have focused on the effect of the MWCNT concentration on the compressive strength of MWCNT-cement composites. As evident in the above discussion of the published literature, well-established research on the compressive strength of mortar mixed with CNTs has not been reported. Furthermore, the findings that have been published vary even when the same parameters are analyzed.

The aim of the present study is to analyze improvements in strength when cement mortar is mixed with MWCNTs. To this end, specimens were prepared using the same mixing method while four experimental parameters, all of which are

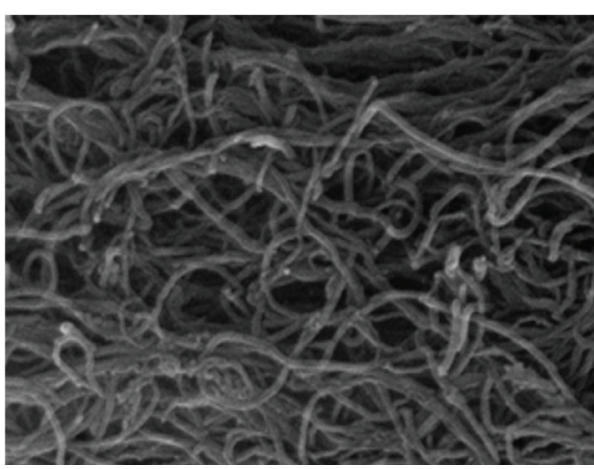

FIGURE 1: SEM image of the MWCNTs.

predicted to affect the compressive strength of MWCNTcement composites, were varied. The first three parameters considered are the MWCNT concentration (varied from $0.25 \mathrm{wt} \%$ to $1.0 \mathrm{wt} \%)$, the curing age $(7,14$, and 28 days), and the ratio of water to cement (denoted as the $\mathrm{W} / \mathrm{C}$ ratio and varied from 0.35 to 0.70 ). The final parameter considered is the MWCNT concentration control method. Here, MWCNT solutions were prepared by either adjusting the MWCNT content during mixing or controlling the MWCNT concentration by adding distilled water to a solution with a high concentration of MWCNTs. A total of 170 cubic mortar specimens were fabricated and tested so as to evaluate the compressive strength as the aforementioned parameters were varied. The microstructure of the MWCNT-cement composites was also analyzed via SEM imaging.

\section{Experimental Program}

When fabricating mortar by mixing MWCNTs with cement, it is essential to disperse the MWCNT solution uniformly within the cement mortar. Because MWCNTs consist of bonds between carbon atoms, they are hydrophobic and thus dispersion in the cement composite is unlikely to be uniform. In the present study, this problem was solved via a chemical surface treatment involving the use of a surfactant [12]. MWCNT solutions were prepared by sonication [6], and dispersion of the MWCNTs was confirmed through SEM imaging, as shown in Figure 1. The MWCNTs employed in the present study had a length of $15 \mu \mathrm{m}$ and a diameter of $5 \mathrm{~nm}$.

For compressive strength testing, cubic specimens with dimensions of $50 \mathrm{~mm} \times 50 \mathrm{~mm} \times 50 \mathrm{~mm}$ were prepared in accordance with the cement compressive strength test standard suggested by ASTM C-109 [13]. Prior to fabricating the mortar specimens, foreign matter and moisture in the cubic mold, tamping rod, and the mixer were removed. Portland cement (Type 1) and standard sand were then mixed at a weight ratio of $1: 2.5$, as shown in Figures 2(a) and 2(b). The ratio of the MWCNT solution weight to the cement weight (i.e., the $\mathrm{W} / \mathrm{C}$ ratio) was varied from 0.35 to 0.70 . Mixtures of aqueous MWCNT solutions, cement, and standard sand were mixed for $4 \mathrm{~min}$ in a mixer with a maximum electric power of $700 \mathrm{~W}$. The cement mortar was then placed in a mold and compacted for approximately $20 \mathrm{~s}$, as shown in Figure 2(d). 


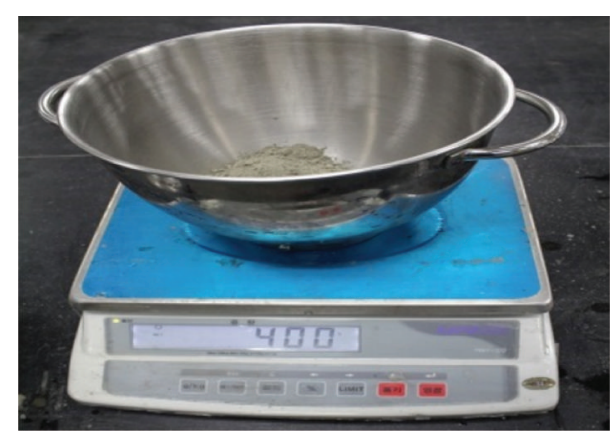

(a) Weighing of cement

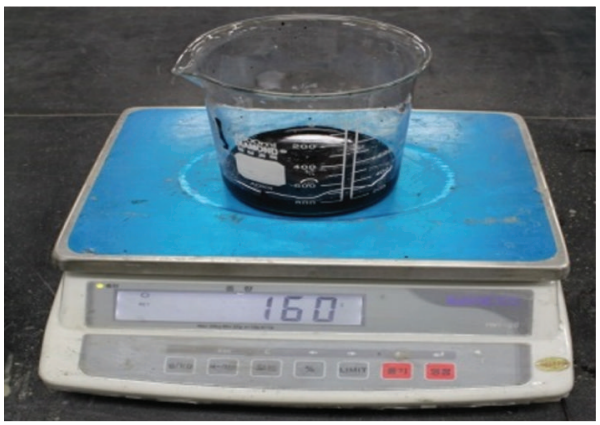

(c) Weighing of MWCNT solution

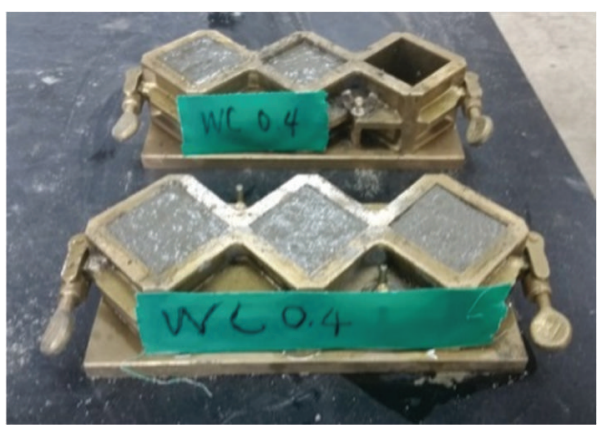

(e) Placement of cement mortar

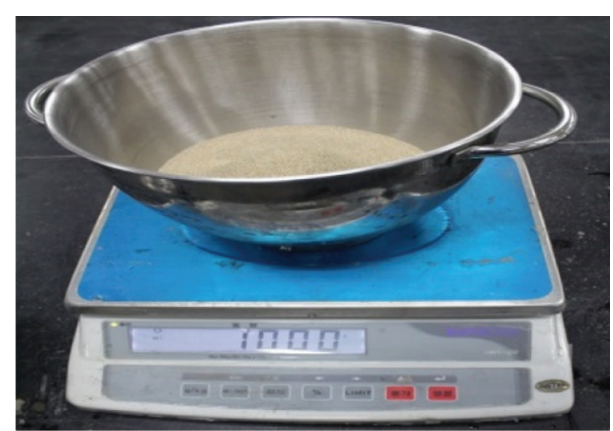

(b) Weighing of standard sand

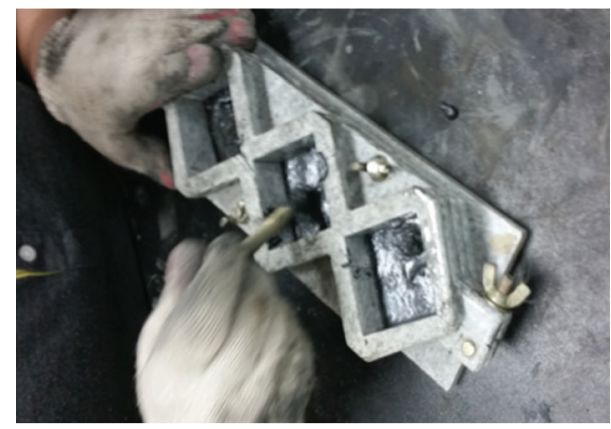

(d) Tamping

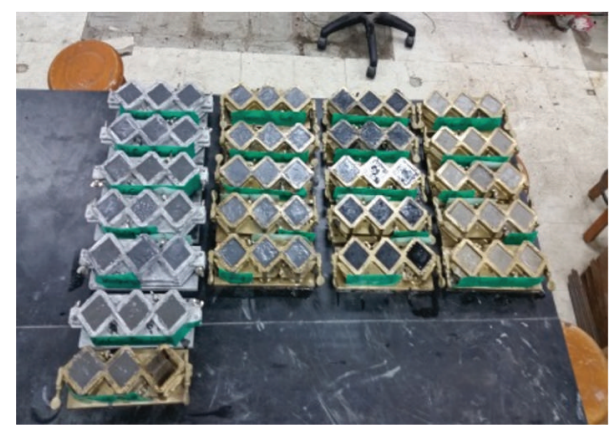

(f) As-processed specimens

FIGURE 2: Specimen fabrication procedure.

Once compacted, the specimens were stored in a temperature chamber for $24 \mathrm{~h}$ (Figure 2(f)), followed by water curing to the specified curing age. After water curing, all moisture on the specimen surface was eliminated by drying and byproducts were subsequently removed. Figure 3 shows both the as-processed MWCNT mortar specimens and the OPC mortar samples. Compressive strength tests were conducted by properly inserting the specimens into a universal testing machine (UTM), as displayed in Figure 4; a rate of $1 \mathrm{~mm} / \mathrm{min}$ was maintained during the tests using the displacementcontrol method.

\section{Test Parameters}

As mentioned above, the compressive strength of the composite specimens was analyzed according to the MWCNT concentration, W/C ratio, curing age, and MWCNT concentration control method; five specimens were prepared to study the influence of each parameter. To minimize variation and obtain reliable experimental results, the compressive strength was calculated as the result of three average test values after excluding maximum and minimum values.

The experimental parameters for the specimens, which are divided into six groups, are given in Table 1. The first group consisted of OPC mortar specimens with increasing $\mathrm{W} / \mathrm{C}$ ratios from 0.35 to 0.70 at 0.05 intervals so as to compare the early-age strength after 7 days of curing. The second group compared the compressive strength of composites with W/C ratios of $0.4,0.5$, and 0.6 after 14 and 28 days of curing. The third group was identical to the first group, except that the early-age strength of the specimens was compared using various $\mathrm{W} / \mathrm{C}$ ratios, a MWCNT concentration of $1.0 \mathrm{wt} \%$, and a curing age of 7 days. The fourth group was identical to the second group, except that the cement was mixed with $1.0 \mathrm{wt} \%$ MWCNTs. In other words, the compressive strength of the samples cured for 14 and 28 days was measured when the 
TABLE 1: Test parameters.

\begin{tabular}{|c|c|c|c|c|c|}
\hline Parameter group & Specimen name & Nanostructure & Concentration (wt\%) & $\mathrm{W} / \mathrm{C}$ ratio & Curing age (days) \\
\hline \multirow{8}{*}{ Group 1} & N-WC35-7 & - & - & 0.35 & \multirow{8}{*}{7} \\
\hline & N-WC40-7 & - & - & 0.40 & \\
\hline & N-WC45-7 & - & - & 0.45 & \\
\hline & N-WC50-7 & - & - & 0.50 & \\
\hline & N-WC55-7 & - & - & 0.55 & \\
\hline & N-WC60-7 & - & - & 0.60 & \\
\hline & N-WC65-7 & - & - & 0.65 & \\
\hline & N-WC70-7 & - & - & 0.70 & \\
\hline \multirow{6}{*}{ Group 2} & N-WC40-14 & - & - & 0.4 & \multirow{3}{*}{14} \\
\hline & N-WC50-14 & - & - & 0.5 & \\
\hline & N-WC60-14 & - & - & 0.6 & \\
\hline & N-WC40-28 & - & - & 0.4 & \multirow{3}{*}{28} \\
\hline & N-WC50-28 & - & - & 0.5 & \\
\hline & N-WC60-28 & - & - & 0.6 & \\
\hline \multirow{8}{*}{ Group 3} & C-10-WC35-7 & MWCNT & 1.0 & 0.35 & \multirow{8}{*}{7} \\
\hline & C-10-WC40-7 & MWCNT & 1.0 & 0.40 & \\
\hline & C-10-WC45-7 & MWCNT & 1.0 & 0.45 & \\
\hline & C-10-WC50-7 & MWCNT & 1.0 & 0.50 & \\
\hline & C-10-WC55-7 & MWCNT & 1.0 & 0.55 & \\
\hline & C-10-WC60-7 & MWCNT & 1.0 & 0.60 & \\
\hline & C-10-WC65-7 & MWCNT & 1.0 & 0.65 & \\
\hline & C-10-WC70-7 & MWCNT & 1.0 & 0.70 & \\
\hline \multirow{6}{*}{ Group 4} & C-10-WC40-14 & MWCNT & 1.0 & 0.40 & \multirow{3}{*}{14} \\
\hline & C-10-WC50-14 & MWCNT & 1.0 & 0.50 & \\
\hline & C-10-WC60-14 & MWCNT & 1.0 & 0.60 & \\
\hline & C-10-WC40-28 & MWCNT & 1.0 & 0.40 & \multirow{3}{*}{28} \\
\hline & C-10-WC50-28 & MWCNT & 1.0 & 0.50 & \\
\hline & C-10-WC60-28 & MWCNT & 1.0 & 0.60 & \\
\hline \multirow{3}{*}{ Group 5} & C-1005-WC50-7 & MWCNT & $1.0 \rightarrow 0.5$ & 0.50 & \multirow{3}{*}{7} \\
\hline & C-07505-WC50-7 & MWCNT & $0.75 \rightarrow 0.5$ & 0.50 & \\
\hline & C-05-WC50-7 & MWCNT & 0.5 & 0.50 & \\
\hline \multirow{3}{*}{ Group 6} & C-075-WC50-7 & MWCNT & 0.75 & 0.50 & \multirow{3}{*}{7} \\
\hline & C-05-WC50-7 & MWCNT & 0.50 & 0.50 & \\
\hline & C-025-WC50-7 & MWCNT & 0.25 & 0.50 & \\
\hline
\end{tabular}

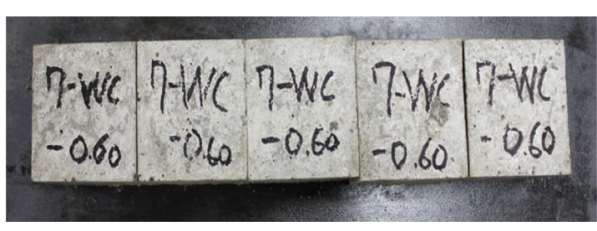

(a) OPC mortar

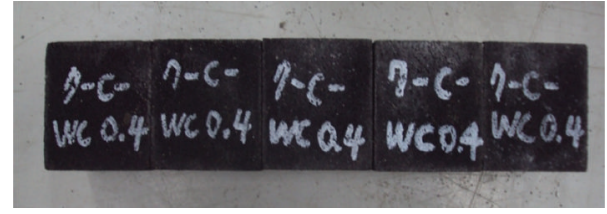

(b) MWCNT-cement mortar

Figure 3: Photographs of the mortar specimens.

$\mathrm{W} / \mathrm{C}$ ratio was $0.4,0.5$, and 0.6 . In the fifth group, distilled water was added to solutions with MWCNT concentrations of $1.0 \mathrm{wt} \%$ and $0.75 \mathrm{wt} \%$ so as to adjust the MWCNT content to $0.5 \mathrm{wt} \%$. To compare only the concentration adjustment methods, the $\mathrm{W} / \mathrm{C}$ ratio and curing age of the fifth group were fixed at 0.5 and 7 days, respectively. Finally, the compressive strength of the sixth group was analyzed after fixing the W/C ratio and curing age at 0.5 and 7 days, respectively, while maintaining a MWCNT concentration of $0.25 \mathrm{wt} \%, 0.5 \mathrm{wt} \%$, or $0.75 \mathrm{wt} \%$. As shown in Table 1 , the specimens in this work were named according to the major parameter under consideration. 


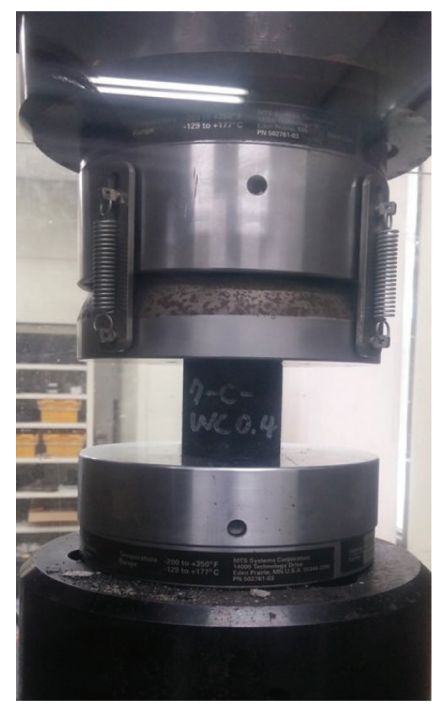

Figure 4: Test setup for evaluating the compressive strength.

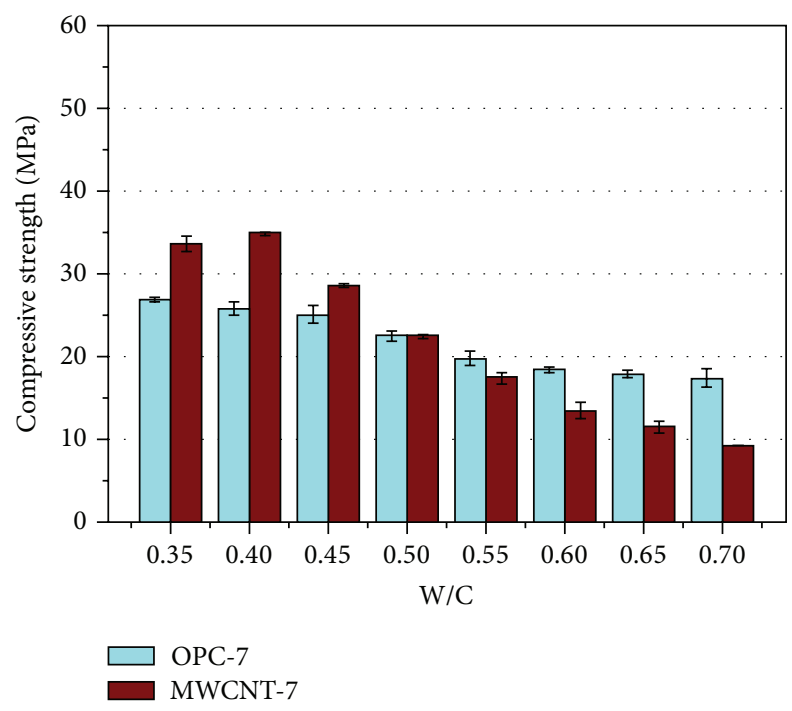

FIGURE 5: Compressive strength for various W/C ratios.

\section{Experimental Results}

Figure 5 compares the compressive strengths of OPC mortar and mortar with $1.0 \mathrm{wt} \%$ MWCNTs after curing for 7 days. In general, the compressive strength decreased as the $\mathrm{W} / \mathrm{C}$ ratio increased. The strength of the MWCNT mortar was found to be lower than that of ordinary mortar when the $\mathrm{W} / \mathrm{C}$ ratio was 0.55 or greater. In contrast, when the $\mathrm{W} / \mathrm{C}$ ratio was 0.4 , the strength of the MWCNT mortar was $25 \%$ greater than that of ordinary mortar. Upon increasing the W/C ratio to 0.70 , the strength of the MWCNT mortar was found to be $48 \%$ lower than that of ordinary mortar. It is believed that, for specimens with high water content, a decrease in compressive strength occurs because the MWCNTs interrupt hydration within the cement during the initial stages of curing, thereby inducing weak coherence between the hydration materials. From a series of compressive strength tests, the threshold

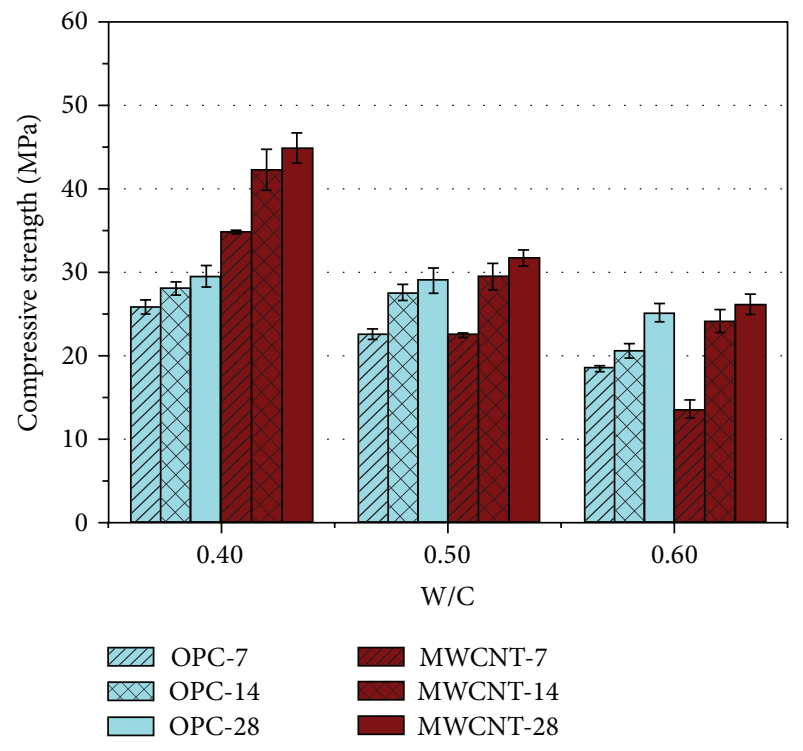

FIGURE 6: Compressive strength for various curing ages.

ratio of water to cement was determined to be 0.4 when the MWCNT concentration is $1.0 \mathrm{wt} \%$.

Figure 6 shows the compressive strength of OPC and MWCNT mortars as a function of the curing age. For all considered $\mathrm{W} / \mathrm{C}$ ratios, the compressive strengths of the OPC and MWCNT mortars increased as the curing age increased. When compared to the OPC mortar, the improvement in strength was greater in the mortar with MWCNT as the curing age increased. The strength enhancement for the MWCNT mortar was particularly significant between 7 and 14 days. After 28 days of curing, the compressive strength of the MWCNT mortar was $34 \%, 8 \%$, and $4 \%$ greater than that of the OPC mortar when the $\mathrm{W} / \mathrm{C}$ ratio was $0.4,0.5$, and 0.6 , respectively. It is clear that the use of a low $\mathrm{W} / \mathrm{C}$ ratio in the MWCNT mortar was more effective in terms of strength improvement than a higher $\mathrm{W} / \mathrm{C}$ ratio. This is because, in the MWCNT mortar with lower water content, the MWCNTs had a bridging effect on voids in the hydration material, thereby increasing coherence inside the cement mortar.

To compare MWCNT concentration control methods, solutions were prepared by either adjusting the MWCNT content during mixing or controlling the MWCNT concentration by adding distilled water to a solution with a high MWCNT content. Specimens whose concentrations had been adjusted to $0.5 \mathrm{wt} \%$ were fabricated by mixing distilled water into $1.0 \mathrm{wt} \%$ and $0.75 \mathrm{wt} \%$ MWCNT solutions; changes in strength were subsequently analyzed. The compressive strength of the samples was compared to that of control group specimens fabricated with a solution that originally had a $0.5 \mathrm{wt} \%$ MWCNT concentration; the results are shown in Figure 7. The difference between the test group and the control group was less than 5\%, which implies that mixing distilled water into the MWCNT solutions does not have a significant effect on strength. Thus, the strength of MWCNT mortar is minimally affected even if a solution of lower 


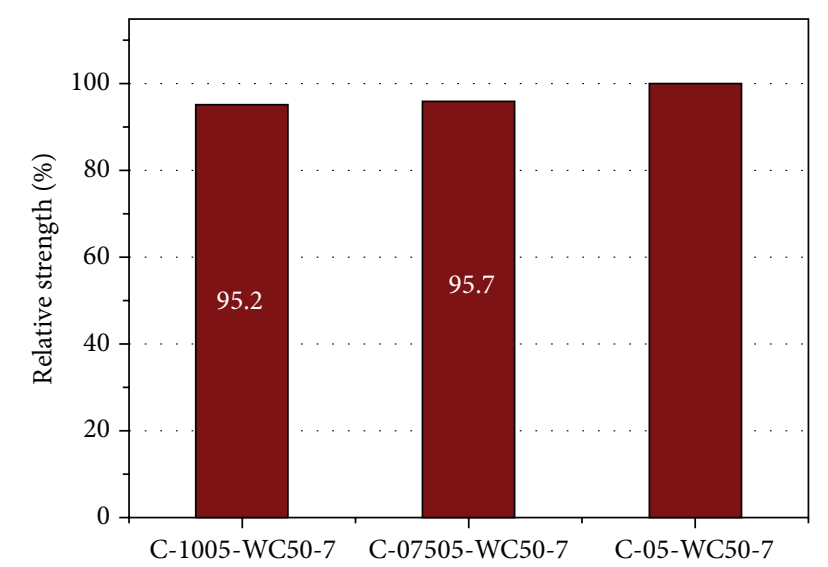

FIGURE 7: Compressive strength for different concentration control methods.

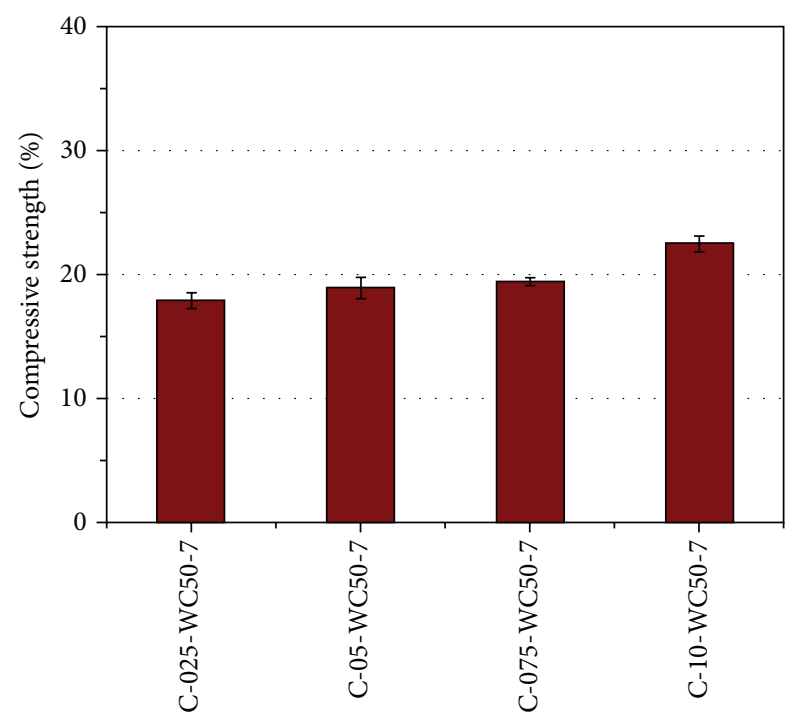

FIGURE 8: Compressive strength for various MWCNT concentrations.

concentration is prepared by mixing distilled water into a MWCNT solution with a higher MWCNT concentration.

Figure 8 presents the compressive strength results obtained for MWCNT mortar cured for 7 days as a function of the MWCNT concentration. The compressive strength tended to increase somewhat as the MWCNT solution concentration increased. In particular, the compressive strength was approximately $26 \%$ greater when the MWCNT concentration was increased from $0.25 \mathrm{wt} \%$ to $1.0 \mathrm{wt} \%$. In other words, even with a fourfold increase in the MWCNT concentration, the increase in compressive strength is merely 26\%. This implies that a lower MWCNT concentration can sometimes be more effective for obtaining a desirable level of strength. It should be noted that the test results presented here are valid for relatively early-age (7 days) mortar. Research to determine the relationship between the MWCNT concentration and compressive strength for completely hardened mortar (28 days or more) is currently underway.

\section{SEM Cross-Sectional Imaging}

In the present study, MWCNT mortar samples were analyzed via SEM so as to investigate the bridging effect between microcracks and the degree of MWCNT dispersion in the cement. Figures 9(a)-9(c) display cross-sectional images acquired for specimen C-10-WC40-28 at magnifications of 5000, 10000, and 30000 times, respectively. This sample showed a significant improvement in strength when compared to OPC mortar.

The magnified image shows the hexagonal structure of calcium hydroxide, needle-like morphology of ettringite, and sheet-like arrangement of calcium-silicate-hydrate (C-S-H). The cement was settled with chemical products such as $\mathrm{C}$ $\mathrm{S}-\mathrm{H}$ and calcium hydroxide, and the cross-sectional image reveals effective dispersion of the MWCNTs in the cement mortar without agglomeration. Figure 9(c) shows evidence of MWCNTs bridging crack gaps in the cement mortar. The C-S-H in the specimen exists in the form of standalone clusters that are joined together by many needle-like hydrates. Furthermore, calcium hydroxides are distributed in the cement mortar, and MWCNTs are observed around pores and microcracks. It is widely known that microcracks and porosity localize the stress concentration. The improvement in strength for the sample in Figure 9 is due to the reduced porosity of the cement mortar, as a higher pore concentration has an adverse effect on strength. It was thus confirmed that MWCNTs improve the compressive strength of cement by inducing a bridging effect in the hydration materials.

\section{Conclusions}

In this work, experiments were conducted to improve the compressive strength of cement mortar by adding MWCNTs. The MWCNT concentration, W/C ratio, curing age, and MWCNT concentration adjustment method were selected as experimental parameters, and their influence on the strength of MWCNT-cement mortar was evaluated. The following conclusions were derived based on the obtained results.

(1) The compressive strength of MWCNT mortar was generally greater than that of OPC mortar. This appears to be the case because as the curing age is increased, the MWCNTs are dispersed above the hydration material like a net, thereby preventing the progression of microcracks within the cement mortar via a bridging effect. Moreover, the compressive strength increased due to a reduction in the space between the voids of the hydration material.

(2) The compressive strength of specimens cured for 7 days with $\mathrm{W} / \mathrm{C}$ ratios above 0.55 was greater than that of OPC mortar. Furthermore, the compressive strength tended to improve with increased curing age when the $\mathrm{W} / \mathrm{C}$ ratio was 0.5 and 0.6 . However, once the curing period elapsed, effective dispersion of 


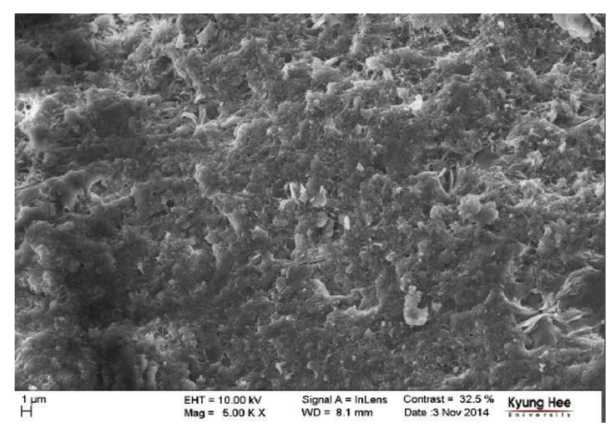

(a) $5,000 x$

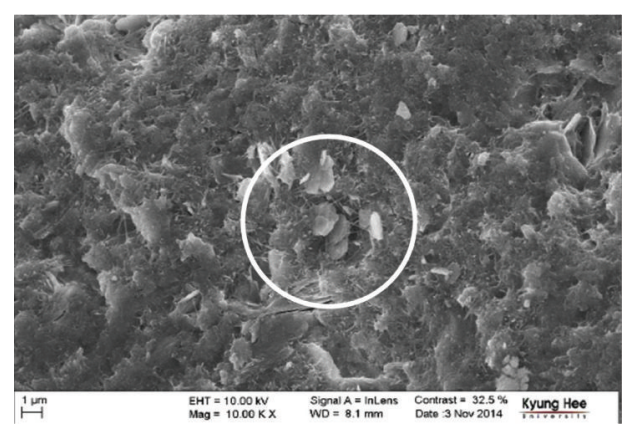

(b) $10,000 x$

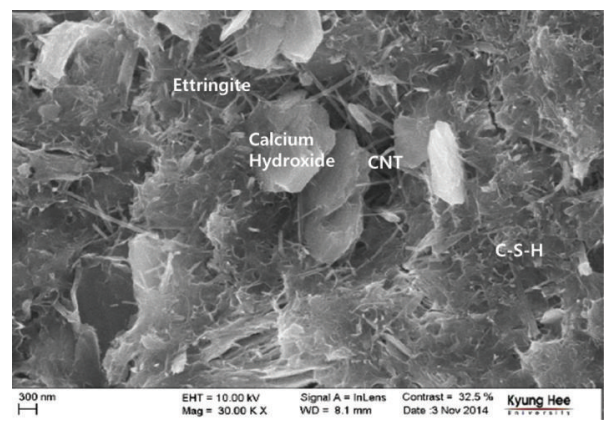

(c) $30,000 x$

FIGURE 9: SEM images obtained for specimen C-10-WC40-28.

the MWCNTs led to a compressive strength that was greater than that of OPC mortar.

(3) An analysis of the compressive strength for samples prepared with various MWCNT solution concentrations in the range of $0.25 \mathrm{wt} \%$ to $1.0 \mathrm{wt} \%$ showed that a higher MWCNT content enhanced the compressive strength of cement. However, the increase in compressive strength was not linearly proportional to the rise in MWCNT concentration. In the present study, a fourfold increase in the MWCNT concentration led to a $26 \%$ increase in strength.

(4) When the MWCNT concentration was lowered by adding distilled water to an aqueous MWCNT solution (i.e., adjusting the concentration of 1.0 or $0.75 \mathrm{wt} \%$ solutions to $0.5 \mathrm{wt} \%$ ), the change in compressive strength was insignificant when compared to that of an MWCNT solution with an original concentration of $0.5 \mathrm{wt} \%$. Such a scenario seems to arise because the additional distilled water has a relatively negligible impact on agglomeration or dispersion.

(5) An analysis of the MWCNT cement microstructure from SEM images showed a uniform dispersion of MWCNTs. Furthermore, the generation of hydration materials such as C-S-H, calcium hydroxide, and ettringite did not appear to be interrupted.

(6) In future research, the parameters used to compare the early-age compressive strength after 7 days of curing should be evaluated for longer curing times, and the resulting compressive strength must be compared to that of OPC mortar. Moreover, because the MWCNT concentration was fixed above $1.0 \mathrm{wt} \%$ in this work, relatively low MWCNT concentrations should be tested in order to find the optimum threshold concentration for MWCNT-cement composites.

\section{Conflict of Interests}

The authors declare that there is no conflict of interests regarding the publication of this paper.

\section{Acknowledgments}

The present study is a basic research project conducted with support from the National Research Foundation of Korea through government funds (Ministry of Science, ICT, and Future Planning, no. 2014R1A2A2A01005895) and a grant from the $\mathrm{R} \& \mathrm{D}$ program of the Korea Railroad Research Institute.

\section{References}

[1] G. Y. Li, P. M. Wang, and X. Zhao, "Mechanical behavior and microstructure of cement composites incorporating surfacetreated multi-walled carbon nanotubes," Carbon, vol. 43 , no. 6 , pp. 1239-1245, 2005.

[2] A. Cwirzen, K. Habermehl-Cwirzen, and V. Penttala, "Surface decoration of carbon nanotubes and mechanical properties 
of cement/carbon nanotube composites," Advances in Cement Research, vol. 20, no. 2, pp. 65-73, 2008.

[3] S. Musso, J.-M. Tulliani, G. Ferro, and A. Tagliaferro, "Influence of carbon nanotubes structure on the mechanical behavior of cement composites," Composites Science and Technology, vol. 69, no. 11-12, pp. 1985-1990, 2009.

[4] A. Chaipanich, T. Nochaiya, W. Wongkeo, and P. Torkittikul, "Compressive strength and microstructure of carbon nanotubes-fly ash cement composites," Materials Science and Engineering A, vol. 527, no. 4-5, pp. 1063-1067, 2010.

[5] M. S. Morsy, S. H. Alsayed, and M. Aqel, "Hybrid effect of carbon nanotube and nano-clay on physico-mechanical properties of cement mortar," Construction and Building Materials, vol. 25, no. 1, pp. 145-149, 2011.

[6] S. Kumar, P. Kolay, S. Malla, and S. Mishra, "Effect of multiwalled carbon nanotubes on mechanical strength of cement paste," Journal of Materials in Civil Engineering, vol. 24, no. 1, pp. 84-91, 2012.

[7] R. Hamzaoui, A. Bennabi, S. Guessasma, M. R. Khelifa, and N. Leklou, "Optimal carbon nanotubes concentration incorporated in mortar and concrete," Advanced Materials Research, vol. 587, no. 10, pp. 107-110, 2012.

[8] M. D. C. Camacho, O. Galao, F. J. Baeza, E. Zornoza, and P. Garcés, "Mechanical properties and durability of CNT cement composites," Materials, vol. 7, no. 3, pp. 1640-1651, 2014.

[9] J. Bharj, S. Singh, S. Chander, and R. Singh, "Experimental study on compressive strength of Cement-CNT composite paste," Indian Journal of Pure and Applied Physics, vol. 52, no. 1, pp. 3538, 2014.

[10] M. Tanvir and Y. Nur, "Optimum mix ratio for carbon nanotube in cement mortar," KSCE Journal of Civil Engineering, vol. 1, no. 8, pp. 1997-2015, 2014.

[11] S. T. Kang and S. H. Park, "Experimental study on improving compressive strength of MWCNT reinforced cementitious composites," Journal of the Korea Concrete Institute, vol. 26, no. 1, pp. 63-70, 2014.

[12] B. Krause, M. Mende, P. Pötschke, and G. Petzold, "Dispersability and particle size distribution of CNTs in an aqueous surfactant dispersion as a function of ultrasonic treatment time," Carbon, vol. 48, no. 10, pp. 2746-2754, 2010.

[13] ASTM International, "Standard test method for compressive strength of hydraulic cement mortars (using 2-in. or [50-mm] cube specimens)," Designation C109/C109M, ASTM International, 2013. 

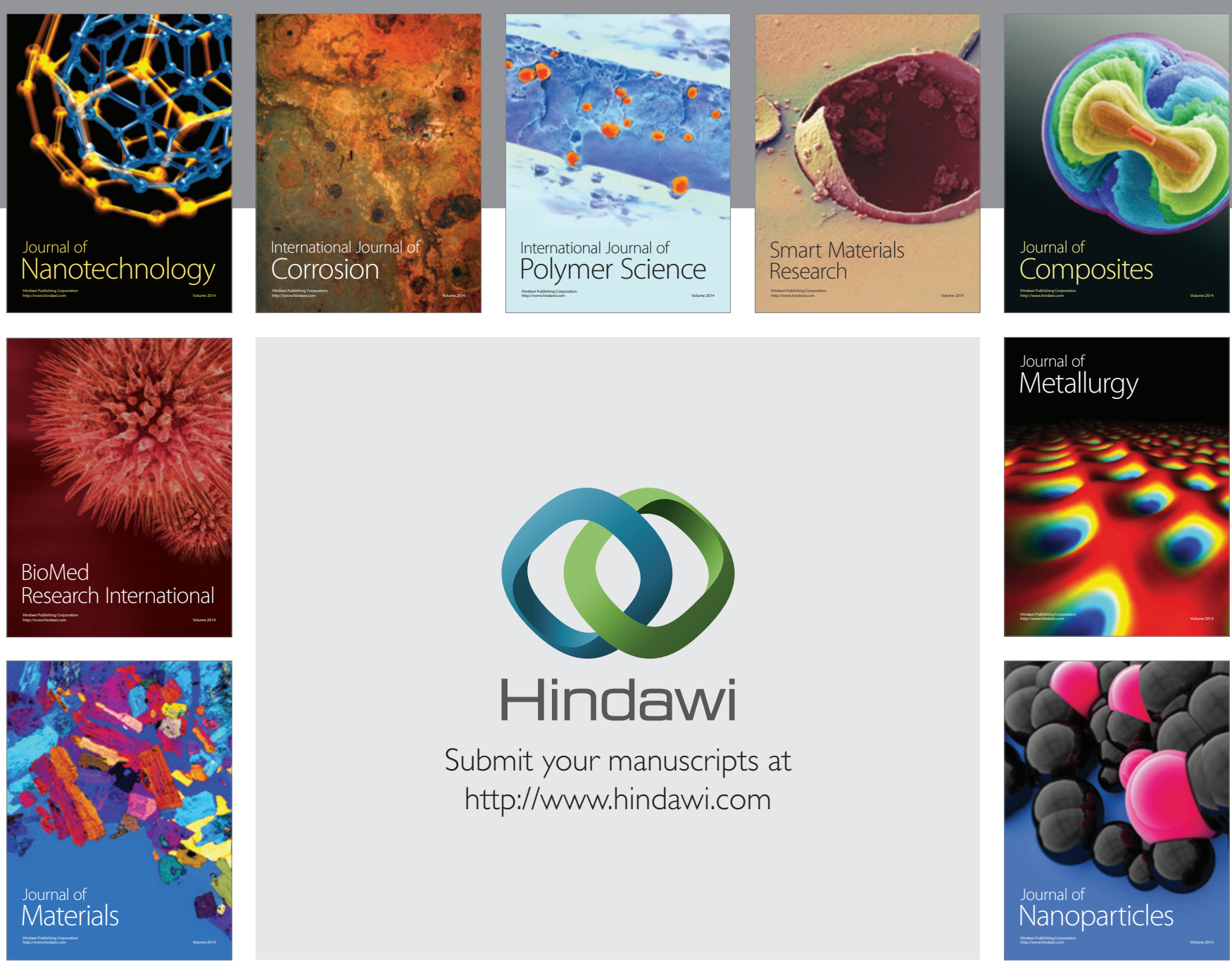

Submit your manuscripts at http://www.hindawi.com
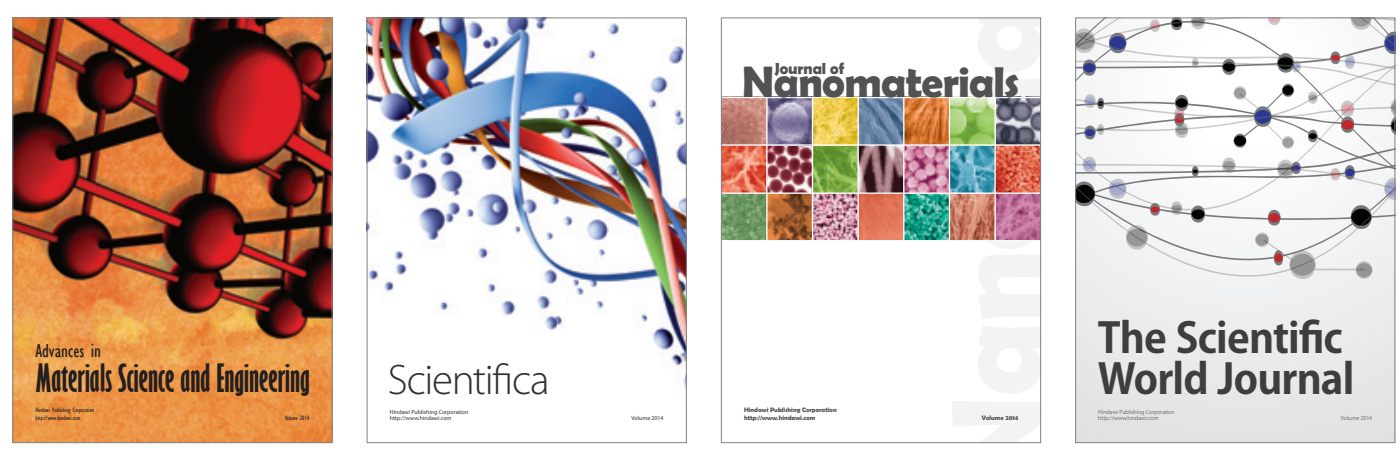

\section{The Scientific World Journal}
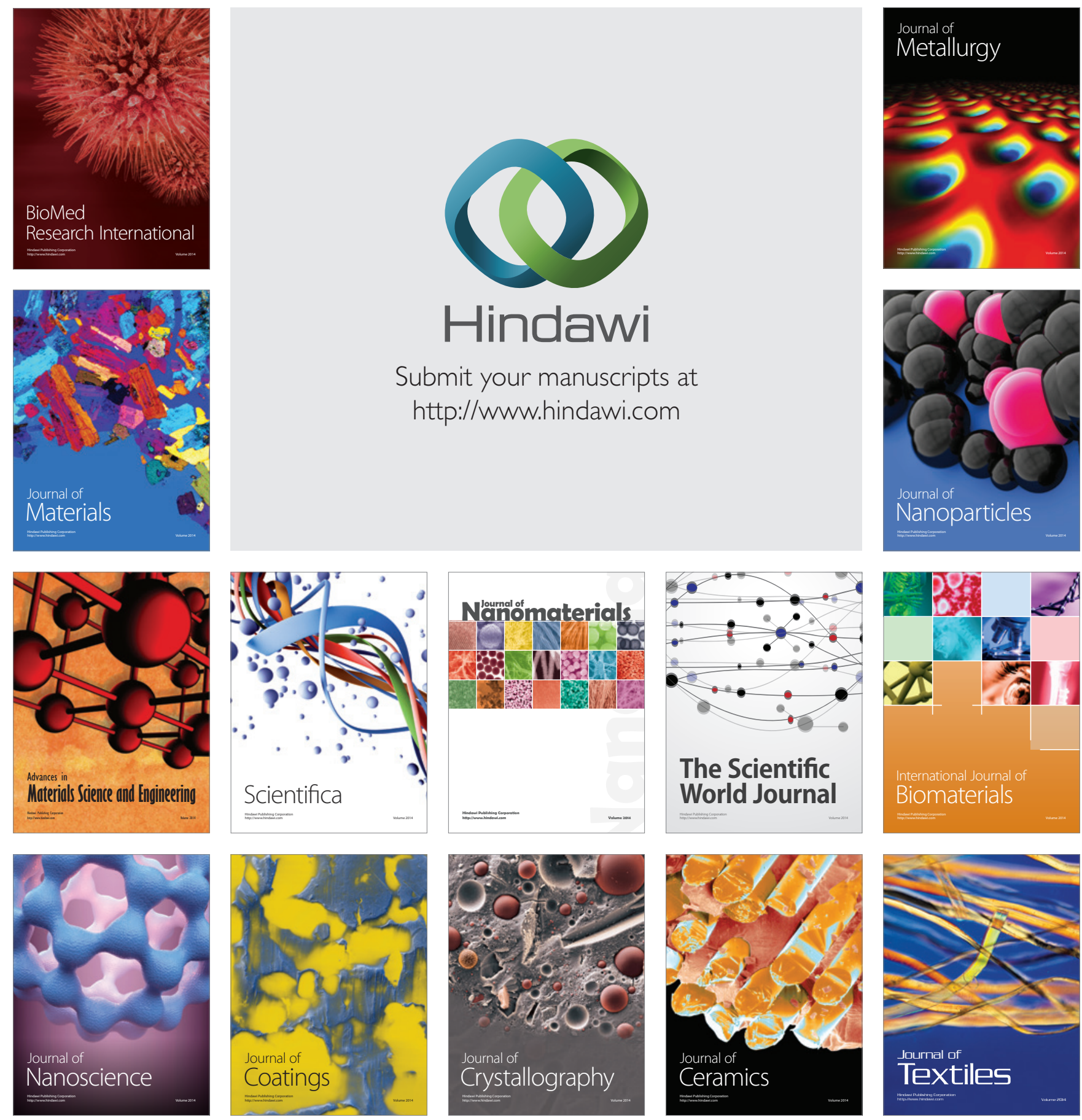